\title{
"The Times They Were A-Changin": A Database-Driven Approach to the Evolution of Harmonic Syntax in Popular Music from the 1960s
}

\author{
HUBERT LÉVEILLÉ GAUVIN [1] \\ Schulich School of Music, McGill University
}

\begin{abstract}
The goal of this research is to investigate the pitch structures of popular music in the 1960 s through a large corpus study in order to identify any consistent changes in harmonic and tonal syntax. More specifically, two studies based on the Billboard DataSet (Burgoyne, Wild \& Fujinaga, 2011; Burgoyne, 2011), a new corpus presenting transcriptions for more than 700 songs, are presented. The first study looks at the incidence of multi-tonic songs throughout the decade, while the second study focuses on the incidence of flat-side harmonies (e.g. bIII, bVI, and bVII) over the same period of time. While no difference was observed in the frequency of multi-tonic songs, the study showed a significant increase in the incidence of flat-side harmonies during the second half of the decade.
\end{abstract}

Submitted 2014 September 16; accepted 2015 April 9.

KEYWORDS: popular music, corpus, Billboard, harmony, modulation

IN January 1964 Bob Dylan released "The Times They Are A-Changin,” a politically-charged protest song encouraging changes in American society. Indeed the 1960s were a time of great political, but also sociological and cultural changes, accompanied by equally important developments in popular music. Many music scholars have addressed the attitudinal shift associated with this period, noting that "[r]ock musicians no longer aspire[d] so much to be professionals and craftspeople" but "artists" (Covach, 2006, p. 38) and that the "later 1960s brought a respect for popular music and a popularity for complex artistic experimentation that had not been matched in any previous era" (Wald, 2009, p. 246).

In recent years, theorists have highlighted specific paradigms of pitch structures in popular music, especially associated with rock. Their observations include an increasing use of modal harmonies and modally-derived chord progressions (Moore, 1992, 1995; Biamonte, 2010), plagal progressions (Temperley, 2011) and an increasing use of chord loops (Tagg, 2009). While these authors seem to agree, at least partially, on some harmonic tendencies that characterize rock music, it is difficult to relate these new idioms to the early pop and rock ' $n$ ' roll music that predates the aforementioned shift. Even though attempts have been made in the past to empirically map these progressions onto a specific timeline (Everett, 2004; de Clercq \& Temperley, 2011, 2013), no previous research has focused on change within a specific decade.

The goal of this research is to investigate pitch-based structures in this repertoire through a large corpus study in order to identify any consistent changes in harmonic and tonal syntax. The Billboard DataSet (Burgoyne, Wild \& Fujinaga, 2011; Burgoyne, 2011) provides a collection of 743 transcriptions of music popular in the United States between 1958 and 1991.[2] The corpus was originally created to "enable significant advances in the quality of training for audio-chord-recognition algorithms" as well as to engage in "computational musicology" (Burgoyne, et al., 2011, p. 633). It consists of a random sampling from all the songs that made the weekly Billboard 100 charts throughout this time period. The content of the corpus is multigenre, primary consisting of rock ' $n$ ' roll, pop/rock, r 'n' b/soul, coutry \& western, vocal, and folk material. Since Billboard is an American standard record chart, most of the songs come from the U.S.A, the U.K., and Canada, though other countries can be represented as well. The transcribing team consisted of more than two dozen people, all university-trained jazz musicians. Each selected song was annotated separately by two different transcribers, then the analyses were reconciled by a third.

Empirically oriented surveys of popular music are becoming more frequent. Perhaps the most important study for the field in recent years is that by de Clercq and Temperley (2011). They presented a 100-song corpus based on Rolling Stone Magazine's "500 Greatest Songs of All Time," compiled in 2004.[3] Their study focused primarily on chord frequency, frequency of root motions, and patterns of co-occurrence between chords.

Although the Billboard DataSet focuses on popular music from the same time period as the 
Rolling Stone corpus, its size is significantly larger. In fact, it is, to my knowledge, the largest collection of methodologically curated transcribed popular music annotations. Furthermore, it focuses on songs that were considered popular in their respective time, instead of songs that were considered important in retrospect. As such, it appeared to be the best available tool for the present research.

Two different aspects of the above-mentioned shift were tested in two different studies, the first dealing with modulation and the second with chord frequency. Since the primary focus of this research is the evolution of harmonic syntax throughout the 1960s, the time period under consideration is 1958 to 1971. These 14 years constitute a sub-corpus of 292 songs. A detailed list of the songs featured in this sub-corpus can be found in the Appendix.

The first study focuses on modulation in the 1960s. Different scholars have discussed modulatory devices in popular music, especially in rock. Everett (1997) mentioned how the "truck driver's" modulation by semitone can be motivated by various reasons, such as "signaling transcendence in a story line," "portray[ing] [...] the passage of time," or "provid[ing] a change of colour for the "big finish." (p. 151). Similarly, Osborn (2013) discussed how "experimental rock artists regularly end songs with completely new material designed to be more memorable than anything previously presented - the terminal climax" and how these "dramatic endings come about through any combination of amplitudinal climax, harmonic modulation, and changing meter." (p. 23). Alternatively, Tagg (2009) noted how dominant modulations are so "indicative of European art music that they can be inserted as genre synecdoches in a context of non-classical harmony (e.g. pop and rock) to connote, seriously or humorously, high art rather than low-brow entertainment, deep feelings and the transcendent rather than the superficial and ephemeral" (p. 111). Considering the premise introduced earlier in this paper that songwriters tried to move from craftspeople to artists during this time period, it is reasonable to think that different devices might have been experimented with to achieve this goal, including modulation. As such, the proposed theory for this first study is that the incidence of songs featuring modulations increased through the decade.

The second study focuses on the frequency of chords bIII, bVI, and bVII[4], the so-called "flat-side" harmonies. As Everett (2001) mentions, "[f]lat-side scale degrees appear primarily within the minor key $[\ldots]$ and through mode mixture in the major key." (p. 53). De Clercq and Temperley (2011) investigated chord frequency, frequency of root motions, patterns of co-occurrence between chords, and melodic organization in popular music. Their findings include a dramatic shift between chords used during the 1950s and the 1960s to 2000s, the 1950s being "completely dominated" (p. 63) by I, IV, and V. Conversely, the authors discussed how, in the 1960s onward, flat-side harmonies bVII, bIII, and bVI "emerge as a group in which all three pairs are highly correlated" (p. 66). These findings match the modal characteristics associated with rock (Moore, 1992, 1995; Everett, 2004; Biamonte, 2010), a genre that became very popular during the late 1960s. Taking into consideration this shift between the 1950s and the later decades, the proposed theory for this second study is that, as we go further into the decade, chords bIII, bVI and bVII increased in frequency.

\section{HYPOTHESES}

Formally, the hypothesis for the first study is:

H1 Songs featuring more than one tonal center will increase in frequency over the studied time period of 1958-1971.

For the second study, the formal hypothesis is:

Songs featuring flat-side harmonies (i.e. bIII, bVI, and bVII) will increase in frequency over the studied time period of 1958-1971.

To anticipate the conclusions, the results were inconsistent with the first hypothesis, but consistent with the second.

\section{METHOD}

\section{Parsing the Database}

The present study relies on the Billboard DataSet, which presents a corpus of harmonic transcriptions for 743 different songs, including 292 in the studied period of 1958-1971. The chronological distribution of the 292 songs is presented in Table 1. 
Table 1: Distribution by year of Songs in the Billboard DataSet for 1958-1971.

\begin{tabular}{|l|l|}
\hline Year & Number of Transcribed Songs \\
\hline $\mathbf{1 9 5 8}$ & 7 \\
\hline 1959 & 14 \\
\hline 1960 & 9 \\
\hline 1961 & 20 \\
\hline 1962 & 27 \\
\hline 1963 & 20 \\
\hline 1964 & 25 \\
\hline 1965 & 20 \\
\hline 1966 & 18 \\
\hline 1967 & 28 \\
\hline 1968 & 26 \\
\hline 1969 & 24 \\
\hline 1970 & 22 \\
\hline 1971 & 32 \\
\hline
\end{tabular}

The transcriptions were created in plain-text format. Each file starts with a header that includes meta-information related to each song: title, artist, meter, and key. Those lines are preceded by the comment character hash ( \# ) to distinguish them from the actual annotation. The notational system used is based on a standardized approach (Harte et al., 2005), with vertical slashes ( | ) used to represent barlines. Each individual line of annotation is preceded by the timestamp of the beginning of the phrase, expressed in seconds. Annotators could freely add other information before or after the vertical slashes, such as form, instrumentation, etc.

This transcription format proved to be polyvalent yet created some obstacles. In order to rapidly and automatically parse through the large number of transcriptions, a UNIX tool was created. This script allows the user to use regular expression (regex, a character string used for patternmatching) to establish proper queries. However, since the files feature extra information such as audio timing and annotators' comments, reading a file as a long single line would fail to have the progressions adjacent to one another. Therefore, the files were processed to remove all inessential information: in every line that started with a comment character (\#) as well as every blank line was kept exactly the same, while in all other lines any characters not enclosed by vertical slashes were removed.

Other problems were linked to using the script. Since the command searches strings of characters, it was impossible in this transcription format to search for a single progression across songs in different keys. Indeed, when dealing with strings of characters, "D:min7 G:7" in C is different from "C:min 7 F:7" in Bb, even though both progressions bear the same relation with their respective tonal center. One way to overcome this problem is to convert the original transcriptions into a tonic-neutral format, where the root of each chord is replaced with integer notation (where $\mathrm{t}$ and e stand for 10 and 11 , respectively). The conversion was done automatically with a second script that relied on custom dictionaries for every possible tonic, including enharmonic equivalence. The script would read the tonic of each song, as notated in the header, decide which dictionary to use, and then convert every root to its neutral equivalent. Songs featuring more than one tonal center (69 in total) were dealt with manually-separated into single-tonic sections, converted using the same procedure, and then reassembled. The newly formatted files were then saved using the same name as their original counterpart, but with a different extension. The new files kept the information in the same order as the original files, allowing the user to easily go back and forth between this format and the original transcriptions. Figures 1.1 and 1.2 show an original transcription and a reformatted one for comparison. 


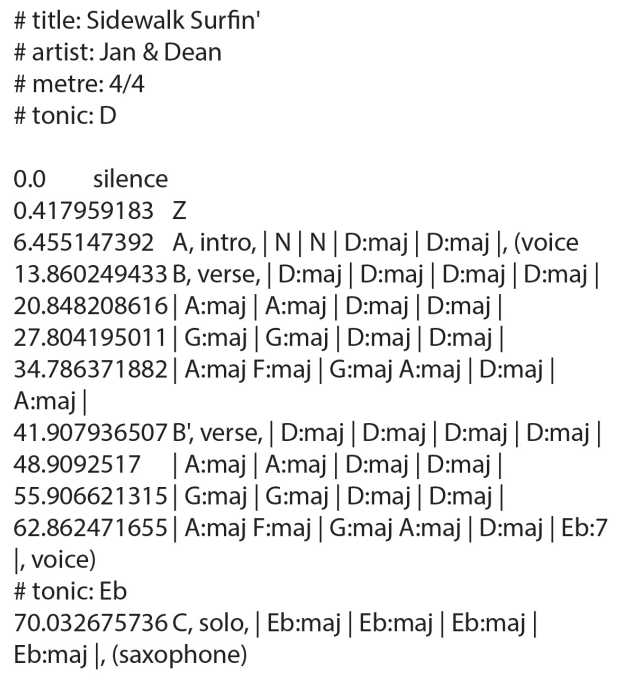

Fig. 1.1. An excerpt of a transcription as presented originally in the Billboard DataSet.

\# title: Sidewalk Surfin'

\# artist: Jan \& Dean

\# metre: $4 / 4$

\# tonic: D

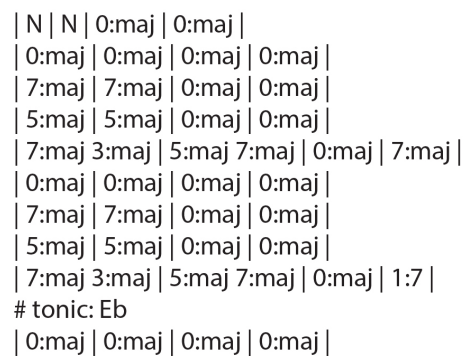

Fig. 1.2. The transcription shown in Fig. 1.1 converted to a tonic-neutral format and cleaned of all nonessential information.

\section{Subdividing the Corpus}

In order to identify any significant changes in harmonic syntax throughout the studied time period, the 14-year time span was divided into two subspans of seven years each: the early 60s (1958-64) and the late 60s (1965-71). Those two subspans contain 122 and 170 songs, respectively. This important difference between the two subspans is due to two main factors. First, the Billboard Hot 100 charts (and thus the database) started in August 1958, whereas all the other years start in January. This explains why the year 1958 features only 7 songs. Second, the random sampling procedure used by Burgoyne et al. created a discrepancy between the different years. Figure 2 reprints Figure 1 from Burgoyne et al. (2011, p. 634) and explains in detail the sampling algorithm used to create the database. While most years in the 14-year period under study feature between 20 and 30 songs, 1959 
and 1960 are outliers with 14 and 9 songs, respectively. Conversely, 1971 features 32 songs, which is higher than average.

This important discrepancy between the two subspans had an impact on the methodology used to analyze the data. Originally, a methodology was designed which aimed to look for gradual linear changes across the whole 14-year period. However, considering that the number of songs available for each year varies substantially, the results would have been distorted by this approach. Instead, a methodology was used which compared the early 60 s with the late 60s, avoiding oversampling any single year due to a larger number of songs in the database for that year, and instead considered broader changes between the beginning and the end of the decade.

1. Divide the set of all chart slots into three eras:

(a) 4 August 1958 to 31 December 1969,

(b) 1 January 1970 to 31 December 1979, and

(c) 1 January 1980 to 30 November 1991.

2. Subdivide the chart slots in each era into five subgroups corresponding to quintiles on the chart:

(a) ranks 1 to 20 ,

(b) ranks 21 to 40 ,

(c) ranks 41 to 60 ,

(d) ranks 61 to 80 , and

(e) ranks 81 to 100 .

3. Select a fixed percentage $p$ of possible chart slots at random from each era-quintile pair.

4. For each selected chart slot:

(a) attempt to acquire the single at the target slot;

(b) if that fails, toss a virtual coin to choose between either the single directly above or directly below the target slot on the chart from the same week;

(c) if that fails, choose the single that was not selected by the coin toss in $4 b$;

(d) if that fails, toss a virtual coin to choose between either the single two ranks above or two ranks below the target single on the chart from the same week;

(e) if that fails, choose the single that was not selected by the coin flip in $4 \mathrm{~d}$; and

(f) if that fails, consider the chart position to be a missing data point.

Figure 1. Sampling algorithm for the Billboard "Hot 100." The algorithm is designed to minimize the distortion from "convenience sampling" while reducing the expense of collecting an audio collection. We believe that this algorithm yields a data set that, as cost-effectively as possible, is valid for drawing conclusions about relative positioning and changes in the behavior of music on the charts over time.

Fig. 2. Sampling algorithm for the Billboard DataSet. Reproduced from Burgoyne et al. (2011). 


\section{RESULTS}

\section{Study 1: Evaluating Modulation Frequency}

The first study focused on modulation. In order to find the number of modulating songs, every file featuring the character string "tonic:" more than once was counted. For example, Jan \& Dean's Sidewalk Surfin', previously presented in Figures 1.1 and 1.2, features two tonics, D and Eb, and so would qualify as a modulating song. Out of the 292 songs searched, 31 multi-tonic songs were found. Figures 3.1. and 3.2 present the distribution of the results.

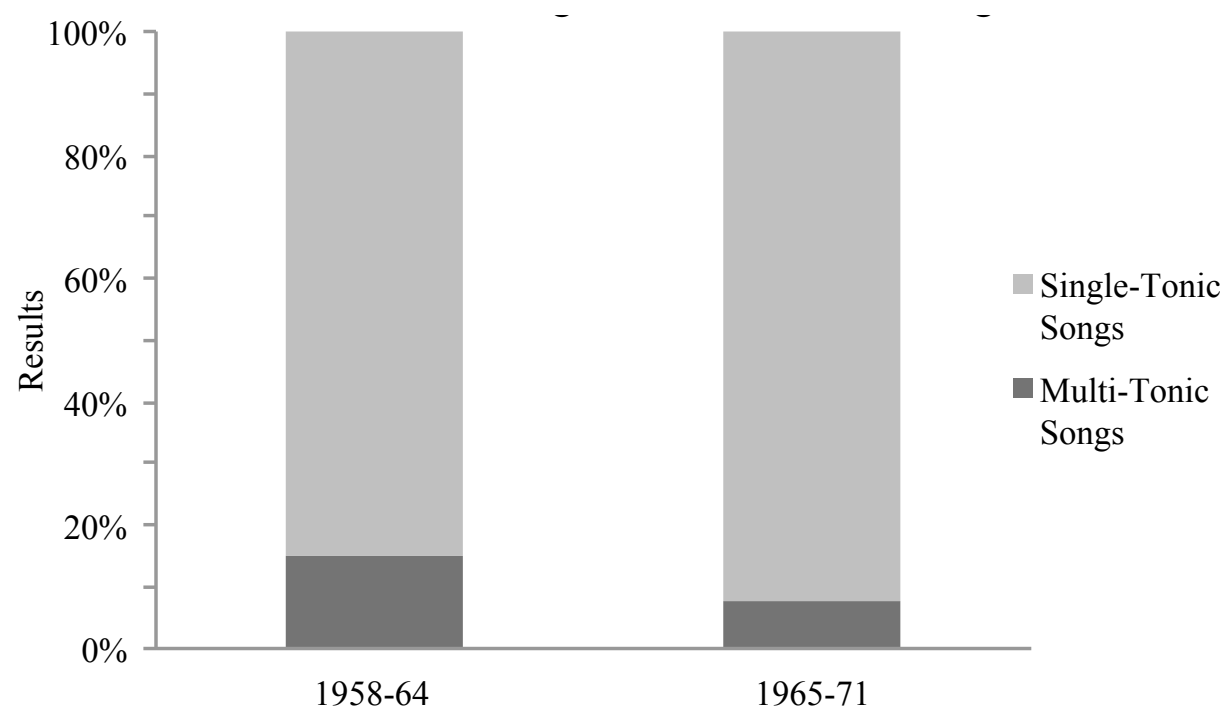

Fig. 3.1. Distribution of single- and multi-tonic songs in the Billboard DataSet between 1958 and 1971, arranged in five-year bins.

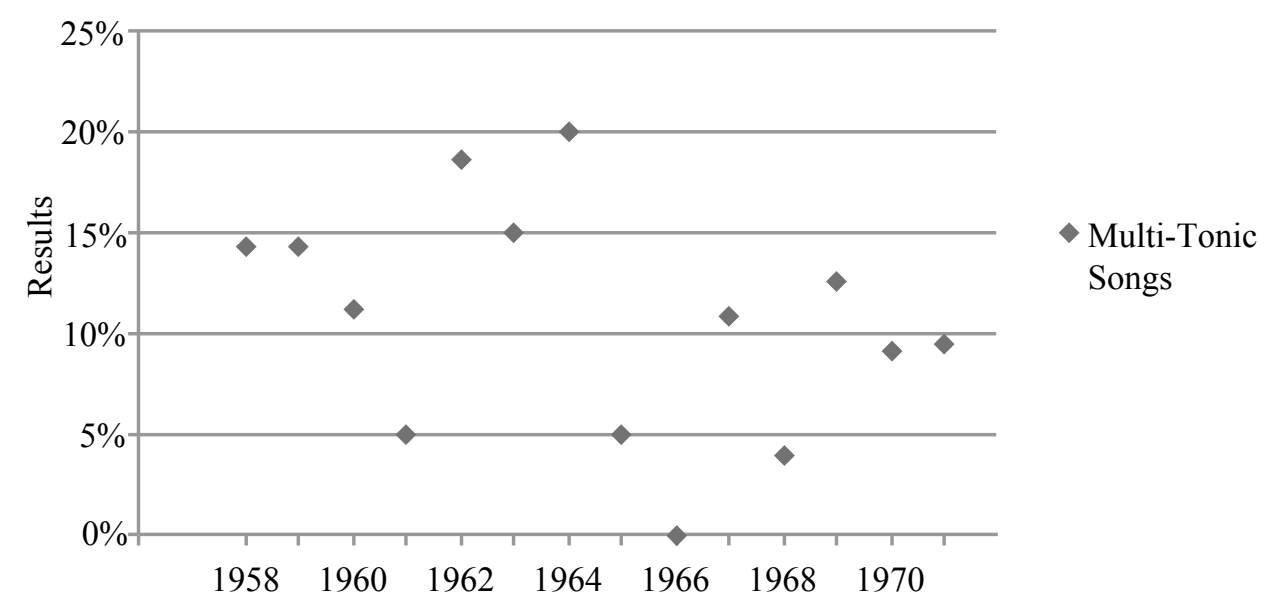

Fig. 3.2. Frequency of multi-tonic songs in the Billboard DataSet between 1958 and 1971, plotted by year.

Using a chi-squared test at a confidence level established at $99 \%$, the difference between the number of multi-tonic songs found in 1958-64 and 1965-71 was not statistically significant $\left(\chi^{2}=3.78\right.$; $\mathrm{df}=1 ; \mathrm{p}=.05)$. As such, there appears to be no significant change in the frequency of multi-tonic songs over time.

\section{Study 2: Evaluating Chord Frequency}

The second study focused on the frequency of flat-side harmonies over time. For the sake of comparison, the frequency of 24 different chords was considered (12 chromatic roots, with either 
major or minor triads). Table 2 shows the overall proportion of songs featuring those chords in each subcategory (i.e 1958-64 and 1965-71). The results for each subcategory were then compared with one another, again using a chi-squared test with a confidence level of $99 \%$. Note that no significance test was done on chords featuring in less than $5 \%$ of the corpus (i.e. bii, biii, \#IV, \#iv, bvi, bvii, VII, vii), as the data collected for those chords was deemed to small to be representative. Due to the way truckdriver's modulations were notated in the Billboard DataSet, many chords immediately preceding a new tonic were originally notated as bVI in the original key, but acted as a tonicization of the tonic in the following key (e.g. V-I in the new key). To address this notational problem, multi-tonic songs featuring at least one bVI chord were manually verified. Songs where the only bVI chord present was immediately before a truck-driver's modulation were not taken into account in the following table. Admittedly, this creates a bias in the data. However, considering that there is no significant difference in the distribution of multi-tonic songs between the early and late $60 \mathrm{~s}$, the bias created appears to be less intrusive than the one created by the original notational process.

The results are summarized in the third column of Table 2. Starred $(*)$ p values indicate statistical significance at the $99 \%$ confidence level.

Table 2: Distribution of songs featuring specific chords (in percentage).

\begin{tabular}{|l|l|l|l|}
\hline & Early 60s (1958-64) & Late 60s (1965-71) & Results \\
\hline I & $98.36 \%$ & $85.29 \%$ & $\chi^{2}=14.45 ; \mathrm{df}=1 ; \mathrm{p}<.01 *$ \\
\hline i & $5.06 \%$ & $22.36 \%$ & $\chi^{2}=15.04 ; \mathrm{df}=1 ; \mathrm{p}<.01 *$ \\
\hline bII & $8.2 \%$ & $5.88 \%$ & $\chi^{2}<.01 ; \mathrm{df}=1 ; \mathrm{p}=.96$ \\
\hline bii & $0 \%$ & $0.59 \%$ & $\mathrm{~N} / \mathrm{A}$ \\
\hline II & $37.71 \%$ & $29.41 \%$ & $\chi^{2}=2.21 ; \mathrm{df}=1 ; \mathrm{p}=.14$ \\
\hline ii & $33.61 \%$ & $35.29 \%$ & $\chi^{2}=0.09 ; \mathrm{df}=1 ; \mathrm{p}=.77$ \\
\hline bIII & $10.66 \%$ & $28.24 \%$ & $\chi^{2}=13.28 ; \mathrm{df}=1 ; \mathrm{p}<.01 *$ \\
\hline biii & $2.46 \%$ & $4.92 \%$ & $\mathrm{~N} / \mathrm{A}$ \\
\hline III & $19.67 \%$ & $18.82 \%$ & $\chi^{2}=.03 ; \mathrm{df}=1 ; \mathrm{p}=.86$ \\
\hline iii & $19.67 \%$ & $20.59 \%$ & $\chi^{2}=.04 ; \mathrm{df}=1 ; \mathrm{p}=.85$ \\
\hline IV & $89.34 \%$ & $83.52 \%$ & $\chi^{2}=1.99 ; \mathrm{df}=1 ; \mathrm{p}=.16$ \\
\hline iv & $13.14 \%$ & $21.18 \%$ & $\chi^{2}=2.51 ; \mathrm{df}=1 ; \mathrm{p}=.11$ \\
\hline \#IV & $4.91 \%$ & $2.36 \%$ & $\mathrm{~N} / \mathrm{A}$ \\
\hline \#iv & $1.64 \%$ & $0 \%$ & $\mathrm{~N} / \mathrm{A}$ \\
\hline V & $96.72 \%$ & $80.59 \%$ & $\chi^{2}=16.71 ; \mathrm{df}=1 ; \mathrm{p}<.01 *$ \\
\hline v & $5.74 \%$ & $15.88 \%$ & $\chi^{2}=7.11 ; \mathrm{df}=1 ; \mathrm{p}=.01 *$ \\
\hline bVI & $9.84 \%$ & $21.77 \%$ & $\chi^{2}=7.24 ; \mathrm{df}=1 ; \mathrm{p}<.01 *$ \\
\hline bvi & $0 \%$ & $1.18 \%$ & N/A \\
\hline VI & $17.21 \%$ & $18.24 \%$ & $\chi^{2}=.05 ; \mathrm{df}=1 ; \mathrm{p}=.82$ \\
\hline vi & $47.54 \%$ & $39.41 \%$ & $\chi^{2}=1.92 ; \mathrm{df}=1 ; \mathrm{p}=.17$ \\
\hline bVII & $13.93 \%$ & $39.41 \%$ & $\chi^{2}=22.5 ; \mathrm{df}=1 ; \mathrm{p}<.01 *$ \\
\hline bvii & $0.82 \%$ & $2.35 \%$ & $\mathrm{~N} / \mathrm{A}$ \\
\hline VII & $4.92 \%$ & $3.52 \%$ & $\mathrm{~N} / \mathrm{A}$ \\
\hline vii & $0.82 \%$ & $2.29 \%$ & $\mathrm{~N} / \mathrm{A}$ \\
\hline
\end{tabular}

The results presented above are consistent with the proposed hypothesis that songs featuring flat-side harmonies (i.e. bIII, bVI, bVII) increase in frequency over the studied time period.

\section{DISCUSSION}

The hypothesis for the first study arose from a simple premise: in order to move from craftspeople to artists, songwriters may have experimented with different compositional devices. As such, it appeared reasonable to question whether modulation was one such device. However, as the results of Study 1 showed, no significant change occurred between the early $60 \mathrm{~s}$ and the late $60 \mathrm{~s}$.

Looking at the results in more detail, three different types of modulations can be distinguished. The first type, though sometimes bearing different names, is the truck driver's modulation: "a sudden shift from one tonal center to another-usually a half step [but sometimes a full step] - that is not functionally related to the first." (Everett, 1997, p. 118, comment in brackets mine). A second type of modulation can be described as a sectional modulation, where a specific section of a song is in a different key from the rest of the piece. With this type of modulation, a song begins and ends in the same tonality. A third type occurs when a song changes key permanently, but with a modulation that is 
not a semitone or a tone. The distribution of these three types of modulation over the 31 multi-tonic songs found between 1958 and 1971 is presented in Figure 4.

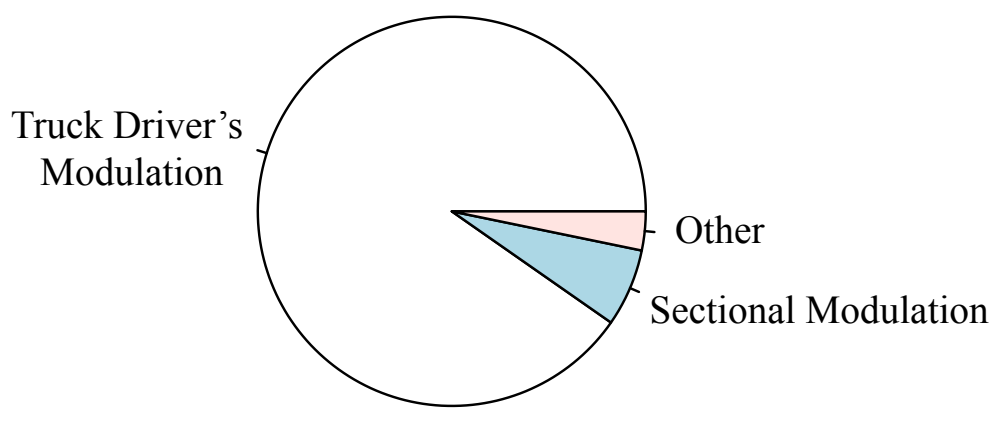

Fig. 4. Distribution of 31 multi-tonic songs between 1958-1971: Truck Driver's Modulation (28 songs, 90.32\%); Sectional Modulation (2 songs, 6.45\%); Other (1 song, 3.23\%).

As shown in Figure 4, the truck driver's modulation is the most frequently used modulation technique between 1958 and 1971 . The majority of the songs (23 songs, $82.14 \%$ ) featuring this type of modulation only modulate once, while songs modulating two ( 3 songs, $10.71 \%)$ or three times $(2$ songs, 7.14\%) are far less frequent. It also appears to be very infrequent for multi-tonic songs with truck driver's modulation to feature both modulations by semitone and by tone (1 song, 3.57\%).

Although the hypothesis for the second study focused on only flat-side harmonies, the frequency of songs featuring 24 different chords was analyzed. As hypothesized, bIII, bVI, and bVII occurred in a significantly greater number of songs in the second half of the decade. A decrease was observed of roughly $15 \%$ in songs featuring major tonic chords (i.e. I), matched by a similar increase in songs featuring minor tonic chords (i.e. i); moreover, minor dominant chords (i.e. v) also increased in frequency in the later $60 \mathrm{~s}$. Although it is not possible at this point to conclude that there is a correlation between both results, it would be worthwhile to follow this lead in future work and investigate whether minor songs become statistically more frequent in the second half of the decade.

\section{Investigating Chord Patterns}

Considering that bIII, bVI, and bVII became more prominent during the second half of the decade, it would be interesting to examine the harmonic context in which they were used. In their study using the Rolling Stone corpus, de Clercq and Temperley (2011) investigated the "frequency of relative-root "trigrams," " using this term to describe "groups of three adjacent chords" (p. 63). Table 3, reprinted from de Clercq and Temperley (2011), shows the most frequent harmonic trigrams ending with a tonic chord, for the 1950s through to the 1990s.

Table 3: Distribution of songs from de Clerq and Temperley's (2011) Rolling Stone corpus with harmonic trigrams ending in the tonic (and not beginning in tonic), in descending order of frequency (reproduced from de Clercq and Temperley, 2011, Table 7).

\begin{tabular}{|l|l|}
\hline Trigram & Instances \\
\hline IV V I & 352 \\
\hline V IV I & 292 \\
\hline bVII IV I & 146 \\
\hline VI IV I & 126 \\
\hline bVII bVI I & 103 \\
\hline bIII bVI I & 66 \\
\hline II V I & 63 \\
\hline bVI bVII I & 60 \\
\hline V VI I & 42 \\
\hline IV bVII I & 39 \\
\hline
\end{tabular}


A similar approach was taken to observe the harmonic syntax involving flat-side harmonies. Using the chords presented in Table 2, every possible permutation featuring at least bIII, bVI, or bVII, and ending with a tonic chord was used to parse the database. However, the methodology differed from the one used by de Clercq and Temperley in two ways: chord mode (major or minor) was taken into account instead of only relative-root motion, and the number of songs featuring a specific progression was calculated, instead of instances of said progression. Chords could occur as simple triads or ornamented with extensions (e.g. maj6, maj7, add9). Moreover, major triads could also occur as dominant seventh or dominant ninth chords. Open-fifth chords ("power chords") were not taken into consideration. The parser was designed to look for continuous strings of characters; as such the search mechanism avoided progressions running over modulations, as both tonalities in the transcription file were separated by a comment line indicating the new key, as shown in Figure 1.2 (e.g. \#tonic: Eb). For this reason, the line preceding the comment line may display some odd progressions, as the last chord of such lines is usually used to modulate to the new key. However, since the number of songs featuring a specific progression was taken into account, and not the specific instances of a progression, this potential distortion did not affect the parsing process. The results for the 1958-72 period are presented in Table 4.

Table 4: Distribution of songs from the Billboard DataSet with harmonic trigrams ending in tonic (and not beginning in tonic) and featuring at least one flat-side harmony, in descending order of frequency.

\begin{tabular}{|l|l|l|l|}
\hline Trigram & Early 60s (1958-64) & Late 60s (1965-71) & Total \\
\hline bVII IV I & 0 & 14 & 14 \\
\hline bVII V I & 4 & 8 & 12 \\
\hline bIII IV I & 1 & 4 & 5 \\
\hline bVI V i & 0 & 5 & 5 \\
\hline bIII V I & 1 & 3 & 4 \\
\hline bVI V I & 3 & 1 & 4 \\
\hline
\end{tabular}

The table presented above gives us a more detailed account of how flat-side harmonies were used during the decade. Although it has been established previously that all three flat-side chords (i.e. bIII, bVI, bVII) increased significantly in frequency throughout the decade, there is a clear preference for the bVII-IV-I trigram. This progression is often referred to as a double plagal progression, as the movement from bVII to IV imitates the plagal movement going from IV to I, as Everett explains:

In the double plagal progression a chain of descending fourth emerges, with a major IV of IV created by lowering the root of a vii chord to b7, creating the bVIIIV-I motion [...] In this chord succession, bVII resolves to IV with a transposed version of the same descending neighbour motions (here 2-1 and b7-6) used by IV in resolving to I (6-5 and 4-3). Originally appearing in 1957-60 as an ornamental guitar figure [...], this function emerged in broader rhythms in the soul music of late 1964 [...] and early 1965 [...] to become rock mainstay. (2009, p. 274).

Everett's comments match very closely the results of this study, with the emergence of the double plagal progression during the late 60 s. His description also exemplifies the modal aspect of the rock genre, suggesting a mixolydian sound created through the flattening of scale degree 7 . The plagal direction of this progression also matches Stephenson's (2001) theory that, "[w]ith regard to harmonic succession, as with cadence placement, rock has, from its beginning, used a style opposed to that of common practice, a style that became increasingly standard during the late 1950s and the 1960s" (p. 103).

Other theorists have seen tonal processes in rock, despite its modal characteristics. For example, Biamonte (2010) has described how bVII-IV-I, along with the Aeolian progression bVIbVII-I, tends to behave tonally: "Although their pitch syntax is not diatonically tonal, in many cases these two characteristic chord patterns express traditional tonal functions such as tonic prolongation and dominant preparation, both of which are often accomplished through elaboration of the tonic by subdominant harmony and cadential resolution." (p. 98).[5] This dual nature of the progression, a modal sound behaving tonally, may explain, at least partially, why this specific pattern was significantly favored over other progressions featuring flat-side harmonies, as it serves as a bridge between common and new practices.

The second most frequent trigram, bVII-V-I, is a modally-mixed progression particularly noticeable for its cross-relation between the flat and natural scale degree seven. This type of crossrelation occurs frequently in progressions using flat-side harmonies, and mostly results from guitar- 
oriented gestures, using parallel barre chords up and down the fretboard. In an article discussing the topography of the guitar and its impact on pop-rock music, Koozin (2011) showed how "physical constraints inherent in guitar playing may shape musical material" (par. 23). Indeed, the same phenomenon happens with bIII-IV-I, bIII-V-I, and bVI-V-I. This reflects the idea that throughout the 1960s, music shifted from being primarily composed on the keyboard to being primarily composed on the guitar. This new practice became heavily associated with rock, so much so that by the late $1970 \mathrm{~s}$, "pop" referred to keyboard-based music while "rock" referred to guitar-based music. (Nobile, 2014, p. 8).

\section{CONCLUSION}

The goal of carrying out the studies presented in this paper was to test whether significant changes in harmonic practices during the 1960s matched the attitudinal shift discussed by popular music scholars. Two studies were conducted, the first focusing on modulating songs, the second focusing on flat-side harmonies. Although the results showed no significant difference between the use of modulation in the first and second half of the decade, there was a significant increase in frequency of flat-side harmonies in the second half of the decade, as hypothesized. However, it would be misleading to assume that this new genre, rock, and its new harmonic practices took over the entire popular music world. Though a new harmonic practice seems to be emerging during the studied period, it does not appear to replace more traditional diatonic harmony, but rather coexists with it. For example, the results presented in Table 4 show bVII-IV-I as the most frequent progression using a flat-side harmony, but the frequency of this progression is still relatively marginal, with only 14 songs out of $170(8.24 \%)$ featuring this progression. By comparison, IV-V-I and V-IV-I, the two most popular diatonic trigrams identified by de Clercq and Temperley in Table 3, were featured in 91 (53.53\%) and $50(29.41 \%)$ songs, respectively. Furthermore, although flat-side harmonies increased in frequency through the decade, they did not do so through clearly established idiomatic progressions, bVII-IV-I and, to a lesser extent, bVII-V-I being exceptions. What may be misleading, then, is the tendency to consider harmonic progressions or songs that were historically significant the norm of a certain time period. Lists such as Rolling Stone's “500 Greatest Songs of All Time," used by de Clercq and Temperley (2011; 2013), are useful to study characteristic tendencies of a specific genre, but fail to give a clear image of a time period as they present songs that were considered historically important $a$ posteriori, and as such, are biased towards innovative or long-lasting, successful songs. When looking at the results presented here, based on a corpus of songs deemed popular in their own time, the attitudinal shift discussed by some scholars appears to be matched with new harmonic practices. However, those new practices established themselves over time.

The two studies presented here focused on very specific aspects of harmonic syntax: modulation and flat-side harmonies. Yet, in order to have a better understanding of the evolution of musical tendencies, other aspects would benefit from a similar empirical approach. Broadening the queries to include progressions that do not necessarily feature tonic chords would help to provide a clearer image of harmonic practices. Similarly, secondary parameters such as hypermeter, form[6], rhythm, and timbre, should be taken into consideration. Although some scholars have looked empirically at those parameters (see Huron \& Ommen, 2006; Serrà, et al., 2012; Biamonte, 2014), they still remain largely under-researched.

\section{ACKNOWLEDGMENTS}

This research project was supported by grants from the Social Sciences and Humanities Research Council of Canada and the Fonds de recherche du Québec - Société et culture. Special thanks go to Nicole Biamonte and Jonathan Wild for their valuable help.

\section{NOTES}

[1] Email correspondence can be addressed to Hubert Léveillé Gauvin at hubert.leveillegauvin@mail.mcgill.ca

[2] Burgoyne et al. explain the basis of the chronological span of this corpus as follows: "The date of the first chart, 4 August 1958, is a natural starting date for selecting songs, but choosing an end date is less straightforward. Hip-hop music does not lend itself readily to harmonic analysis as traditionally understood, and because hip-hop became more popular in the 1990s and 2000s, a larger portion of the music on the 'Hot 100' chart from these periods falls out of the scope of the data set. Furthermore, there have been several changes to the formula for computing the 'Hot 100' over time, including a particularly significant shift in December 1991 [...]”' (Burgoyne, et al., 2011, p. 634) 
[3] Since the publication of their article in 2011, de Clercq and Temperley have expanded their corpus to 200 songs (Temperley \& de Clercq, 2013).

[4] Throughout this paper, roman numeral are shown in relation to major, an approach used by Biamonte (2010), Temperley (2011), de Clercq (2012), Nobile (2014), among many others.

[5] For a more thorough discussion on double plagal progressions, see Everett, 2001, 2004; Carter, 2005; Spicer, 2005; Biamonte, 2010.

[6] Although the annotators working on the Billboard DataSet were encouraged to "use free comments in particular to denote major structural features such as verses, bridges, and choruses" (Burgoyne, 2011, p. 194), those formal labels were not properly curated, which make their use obsolete for anything other then informal discussion.

\section{REFERENCES}

Biamonte, N. (2010). Triadic modal and pentatonic patterns in rock music. Music Theory Spectrum, 32(2), 95-110.

Burgoyne, J. A. (2011). Stochastic processes and database-driven musicology. (Unpublished doctoral dissertation). McGill University, Montreal.

Burgoyne, J.A., Wild, J., \& Fujinaga, I. (2011). An expert ground-truth set for audio chord recognition and music analysis. In A. Klapuri \& C. Leider (Eds.), Proceedings of the 12th International Society for Music Information Retrieval Conference (pp. 633-638). Miami, Florida: University of Miami.

Carter, P. S. (2005). Retrogressive harmonic motion as structural and stylistic characteristic of poprock music. (Unpublished doctoral dissertation). University of Cincinnati, Cincinnati.

Covach, J. (2006). From 'craft' to 'art': Formal structure in the music of the Beatles. In K. Womack \& T. F. Davis (Eds.), Reading the Beatles: Cultural Studies, Literary Criticism, and the Fab Four (pp. 37-53). Albany: State University of New York Press.

de Clercq, T. (2012). Sections and successions in successful songs: A prototype approach to form in rock music. (Unpublished doctoral dissertation). Eastman School of Music, Rochester.

de Clercq, T., \& Temperley, D. (2011). A corpus analysis of rock harmony. Popular Music, 30(1), 4770 .

Everett, W. (1997). Swallowed by a song: Paul Simon's crisis of chromaticism. In J. Covach \& G. M. Boone (Eds.), Understanding Rock: Essays in Musical Analysis (pp. 113-58). Oxford: Oxford University Press.

Everett, W. (2001). The Beatles as Musicians: The Quarry Men through Rubber Soul. Oxford: Oxford University Press.

Everett, W. (2004). Making sense of rock's tonal systems. Music Theory Online, 10(4). Retrieved from http://www.mtosmt.org/issues/mto.04.10.4/mto.04.10.4.w_everett.html

Everett, W. (2009). Foundations of Rock: From 'Blue Suede Shoes' to 'Suite: Judy Blue Eyes.' Oxford: Oxford University Press.

Harte, C. A., Sandler, M. B., Abdallah, S. A. \& Gómez, E. (2005). Symbolic representation of musical chords: A proposed syntax for text annotations. In Proceedings of the 6th International Conference on Music Information Retrieval (pp. 66-71). Retrieved from http://ismir2005.ismir.net/proceedings/1080.pdf

Huron, D., \& Ommen, A. (2006). An empirical study of syncopation in American popular music, 1890-1939. Music Theory Spectrum, 28(2), 211-31.

Koozin, T. (2011). Guitar voicing in pop-rock music: A performance-based analytical approach. Music Theory Online, 17(3). Retrieved from http://www.mtosmt.org/issues/mto.11.17.3/mto.11.17.3.koozin.php 
Moore, A. (1992). Patterns of harmony. Popular Music, 11(1), 73-106.

Moore, A. (1995). The so-called 'flattened seventh' in rock. Popular Music, 14(2), 185-201.

Nobile, D. F. (2014). A structural approach to the analysis of rock music. (Unpublished doctoral dissertation). The City University of New York, New York.

Osborn, B. (2013). Subverting the verse/chorus paradigm: Terminally climatic forms in recent rock music. Music Theory Spectrum, 3(1), 23-47.

Serrà, J., Corral, Á., Boguñá, M., Haro, M., \& Arcos, J. L. (2012). Measuring the evolution of contemporary Western popular music. Scientific Reports, 2. Retrieved from http://www.nature.com/srep/2012/120726/srep00521/full/srep00521.html

Stephenson, K. (2002). What to Listen for in Rock: A Stylistic Analysis. New Haven, CT: Yale University Press.

Spicer, M. (2004). (Ac)cumulative form in pop-rock music. Twentieth Century Music, 1(1), 29-64.

Spicer, M. (2004). Review of Walter Everett, The Beatles as Musicians: The Quarry Men Through Rubber Soul. Music Theory Online, 11(4). Retrieved from http://www.mtosmt.org/issues/mto.05.11.4/mto.05.11.4.spicer.html

Summach, J. (2011). The structure, function, and genesis of the prechorus. Music Theory Online, 17(3). Retrieved from http://www.mtosmt.org/issues/mto.11.17.3/mto.11.17.3.summach.html

Summach, J. (2012). Form in top-20 rock music, 1955-89. (Unpublished doctoral dissertation). Yale University, New Haven.

Tagg, P. (2009). Everyday Tonality: Towards a Tonal Theory of What Most People Hear. New York: Mass Media Scholar's Press.

Temperley, D. (2011). The cadential IV in rock. Music Theory Online, 17(1). Retrieved from http://www.mtosmt.org/issues/mto.11.17.1/mto.11.17.1.temperley.html

Temperley, D., \& de Clercq, T. (2013). Statistical analysis of harmony and melody in rock music. Journal of New Music Research. 2(3), 187-204.

Wald, E. (2009). How the Beatles Destroyed Rock ' $n$ ' Roll: An Alternative History of American Popular Music. Oxford: Oxford University Press.

\section{APPENDIX}

Songs Featured in the 1958-1971 Sub-Corpus

\begin{tabular}{|c|l|l|}
\hline Year & Artist & Title \\
\hline $\mathbf{1 9 5 8}$ & Count Basie & Going to Chicago \\
\hline $\mathbf{1 9 5 8}$ & Chuck Berry & Sweet Little Rock And Roll \\
\hline $\mathbf{1 9 5 8}$ & Johnny Cash & The Ways of a Woman \\
\hline $\mathbf{1 9 5 8}$ & Jimmy Clanton & Just A Dream \\
\hline $\mathbf{1 9 5 8}$ & The Everly Brothers & Bird Song \\
\hline $\mathbf{1 9 5 8}$ & Peggy Lee & Fever \\
\hline $\mathbf{1 9 5 8}$ & Louis Prima \& Keely Smith & That Old Black Magic \\
\hline
\end{tabular}




\begin{tabular}{|c|c|c|}
\hline 1959 & LaVern Baker & I Cried a Tear \\
\hline 1959 & Rod Bernard & This Should Go On Forever \\
\hline 1959 & Chuck Berry & Almost Grown \\
\hline 1959 & Johnny Cash & I Got Stripes \\
\hline 1959 & Ray Charles & (Night Time is) The Right Time \\
\hline 1959 & Fats Domino & Be My Guest \\
\hline 1959 & Fats Domino & I Want to Walk You Home \\
\hline 1959 & Johnny Horton & The Battle of New Orleans \\
\hline 1959 & Johnny Horton & Johnny Reb \\
\hline 1960 & Brenda Lee & Sweet Nothin's \\
\hline 1959 & Elvis Presley & My Wish Came True \\
\hline 1959 & Elvis Presley & One Night \\
\hline 1959 & Cliff Richard & Living Doll \\
\hline 1959 & Santo \& Johnny & Sleep Walk \\
\hline 1959 & Dinah Washington & Unforgettable \\
\hline 1960 & Floyd Cramer & Last Date \\
\hline 1960 & Bing Crosby & Silent Night \\
\hline 1960 & Dion & Where or When \\
\hline 1960 & Jimmy Jones & Handy Man \\
\hline 1960 & Jimmy Reed & Baby What You Want Me to Do \\
\hline 1960 & Charlie Rich & Lonely Weekends \\
\hline 1960 & Marty Robins & Big Iron \\
\hline 1960 & The Ventures & Perfidia \\
\hline 1961 & Gary U.S. Bonds & Quarter to Three \\
\hline 1961 & James Brown & Baby, You're Right \\
\hline 1961 & James Brown & I Don't Mind \\
\hline 1961 & The Crystals & (There's No Other) Like My Baby \\
\hline 1961 & Dion & Runaround Sue \\
\hline 1961 & Roy Drusky & Three Hearts in a Tangle \\
\hline
\end{tabular}




\begin{tabular}{|c|c|c|}
\hline 1961 & The Everly Brothers & Ebony Eyes \\
\hline 1961 & The Everly Brothers & Walk Right Back \\
\hline 1961 & Don Gibson & Sea of Heartbreak \\
\hline 1961 & Etta James & Fool That I Am \\
\hline 1961 & Ben E. King & Amor \\
\hline 1961 & Brenda Lee & Dum Dum \\
\hline 1961 & The Miracles & Mighty Good Lovin' \\
\hline 1961 & Gene Pitney & Town Without Pity \\
\hline 1961 & Elvis Presley & (Marie is the Name) His Latest Flame \\
\hline 1961 & Elvis Presley & Little Sister \\
\hline 1961 & The Shirelles & Will You Love Me Tomorrow? \\
\hline 1961 & The String-A-Longs & Wheels \\
\hline 1961 & Johnny Tillotson & Jimmy’s Girl \\
\hline 1961 & Ike \& Tina Turner & It's Gonna Work Out Fine \\
\hline 1962 & Paul Anka & Love Me Warm and Tender \\
\hline 1962 & The Beach Boys & Surfin' Safari \\
\hline 1962 & Bruce Chanel & Hey! Baby \\
\hline 1962 & Chubby Checker & The Twist \\
\hline 1962 & Nat "King" Cole & Ramblin' Rose \\
\hline 1962 & The Contours & Do You Love Me? \\
\hline 1962 & Bing Crosby & White Christmas \\
\hline 1962 & The Crystals & He's a Rebel \\
\hline 1962 & Bo Diddley & You Can't Judge a Book by the Cover \\
\hline 1962 & Dion & (I Was) Born to Cry \\
\hline 1962 & Dion & Love Came to $\mathrm{Me}$ \\
\hline 1962 & Dion & Lovers Who Wander \\
\hline 1962 & The Falcons & I Found a Love \\
\hline
\end{tabular}




\begin{tabular}{|c|c|c|}
\hline 1962 & The Everly Brothers & That's Old Fashioned (That's the Way Love Should Be) \\
\hline 1962 & Eddie Holland & Jamie \\
\hline 1962 & Etta James & Stop the Wedding \\
\hline 1962 & Gladys Knight \& The Pips & Letter Full of Tears \\
\hline 1962 & Brenda Lee & All Alone Am I \\
\hline 1962 & Brenda Lee & Everybody Loves Me But You \\
\hline 1962 & Brenda Lee & Heart in Hand \\
\hline 1962 & Little Joey \& The Flips & Bongo Stomp \\
\hline 1962 & Jimmy Smith & Walk on the Wild Side (Part 1) \\
\hline 1962 & Hank Snow & I've Been Everywhere \\
\hline 1962 & Bertha Tillman & Oh My Angel \\
\hline 1962 & Johnny Tillotson & It Keeps Right On A-Hurtin' \\
\hline 1962 & Mel Torme & Comin' Home Baby \\
\hline 1962 & Dinah Washington & Where Are You? \\
\hline 1963 & LaVern Baker & See See Rider \\
\hline 1963 & Bobby Bare & Detroit City \\
\hline 1963 & The Beach Boys & In My Room \\
\hline 1963 & Solomon Burke & If You Need Me \\
\hline 1963 & The Chiffons & He's So Fine \\
\hline 1963 & Nat "King" Cole & Those Lazy-Hazy-Crazy Days of Summer \\
\hline 1963 & Dion & Ruby Baby \\
\hline 1963 & Dion & This Little Girl \\
\hline 1963 & The Drifters & On Broadway \\
\hline 1963 & Dave Dudley & Six Days on the Road \\
\hline 1963 & The Fireballs & Sugar Shack \\
\hline
\end{tabular}




\begin{tabular}{|c|c|c|}
\hline 1963 & Etta James & Would It Make Any Difference to You? \\
\hline 1963 & Chris Kenner & Land of the 1000 Dances \\
\hline 1963 & Brenda Lee & Loosing You \\
\hline 1963 & Barbara Lewis & Hello Stranger \\
\hline 1963 & The Moments & Walk Right In \\
\hline 1963 & The Ronettes & Be My Baby \\
\hline 1963 & Johnny Tillotson & Out of My Mind \\
\hline 1963 & Johnny Tillotson & Talk Back Trembling Lips \\
\hline 1963 & Jackie Wilson & Baby Workout \\
\hline 1964 & Louis Armstong & Hello Dolly! \\
\hline 1964 & The Beach Boys & Wendy \\
\hline 1964 & The Beatles & A Hard Day's Night \\
\hline 1964 & The Beatles & Do You Want to Know a Secret? \\
\hline 1964 & The Beatles & I Saw Her Standing There \\
\hline 1964 & The Beatles & Love Me Do \\
\hline 1964 & The Beatles & She's a Woman \\
\hline 1964 & Jan \& Dean & Sidewalk Surfin’ \\
\hline 1964 & Jan \& Dean & $\begin{array}{l}\text { The Anaheim, Azusa \& Cucamonga Sewing Circle, Book } \\
\text { Review And Timing Association }\end{array}$ \\
\hline 1964 & Jan \& Dean & The Little Old Lady (From Pasadena) \\
\hline 1964 & Lesley Gore & You Don’t Own Me \\
\hline 1964 & B.B. King & How Blue Can You Get? \\
\hline 1964 & Brenda Lee & As Usual \\
\hline 1964 & Dean Martin & Everybody Loves Somebody \\
\hline
\end{tabular}




\begin{tabular}{|c|c|c|}
\hline 1964 & Willie Mitchell & $20-75$ \\
\hline 1964 & Elvis Presley & Ask Me \\
\hline 1964 & Ottis Redding & Chained and Bound \\
\hline 1964 & The Rolling Stones & Not Fade Away \\
\hline 1964 & The Rolling Stones & Time Is On My Side \\
\hline 1964 & Barbara Streisand & Funny Girl \\
\hline 1964 & Barbara Streisand & People \\
\hline 1964 & Irma Thomas & Wish Someone Would Care \\
\hline 1964 & Johnny Tillotson & I Rise, I Fall \\
\hline 1964 & Johnny Tillotson & Worried Guy \\
\hline 1964 & J. Frank Wilson \& The Cavaliers & Last Kiss \\
\hline 1965 & Joan Baez & There But For Fortune \\
\hline 1965 & Fontella Bass & Rescue Me \\
\hline 1965 & The Beatles & Eight Days a Week \\
\hline 1965 & The Beatles & Help! \\
\hline 1965 & The Beatles & I Don't Want to Spoil the Party \\
\hline 1965 & James Brown & I Got You (I Feel Good) \\
\hline 1965 & The Castaways & Liar, Liar \\
\hline 1965 & Ray Charles & Crying Time \\
\hline 1965 & Roy Head & Treat Her Right \\
\hline 1965 & Brenda Lee & Too Many Rivers \\
\hline 1965 & Martha \& The Vandellas & Nowhere to Run \\
\hline 1965 & Bobbi Martin & I Love You So \\
\hline 1965 & Dean Martin & I Will \\
\hline 1965 & Buck Owens & I've Got a Tiger by the Tail \\
\hline 1965 & Wilson Pickett & In the Midnight Hour \\
\hline
\end{tabular}




\begin{tabular}{|c|c|c|}
\hline 1965 & Otis Redding & I've Been Loving You Too Long (To Stop Now) \\
\hline 1965 & The Righteous Brothers & Unchained Melody \\
\hline 1965 & Simon \& Garfunkel & The Sounds of Silence \\
\hline 1965 & Sonny \& Cher & Baby Don’t Go \\
\hline 1965 & The Yardbirds & Heart Full of Soul \\
\hline 1966 & The Byrds & Eight Miles High \\
\hline 1966 & Ray Charles & Let's Go Get Stoned \\
\hline 1966 & The Chiffons & Sweet Talkin’ Guy \\
\hline 1966 & Bobby Darin & If I Were a Carpenter \\
\hline 1966 & Donovan & Sunshine Superman \\
\hline 1966 & The Kinks & 'Till the End of the Day \\
\hline 1966 & Brenda Lee & Coming On Strong \\
\hline 1966 & Roger Miller & You Can't Roller Skate in a Buffalo Herd \\
\hline 1966 & Aaron Neville & Tell It Like It Is \\
\hline 1966 & Buck Owens & Think of Me \\
\hline 1966 & Paul Revere \& The Raiders & Kicks \\
\hline 1966 & The Righteous Brothers & (You're My) Soul and Inspiration \\
\hline 1966 & The Rolling Stones & $\begin{array}{l}\text { Have You Seen Your Mother, Baby, Standing In The } \\
\text { Shadow? }\end{array}$ \\
\hline 1966 & Simon \& Garfunkel & A Hazy Shade of Winter \\
\hline 1966 & Nancy Sinatra & These Boots Are Made For Walkin’ \\
\hline 1966 & Swingin' Medallions & Double Shot (Of My Baby’s Love) \\
\hline 1966 & The Temptations & Ain't Too Proud to Beg \\
\hline
\end{tabular}




\begin{tabular}{|c|c|c|}
\hline 1966 & The Yardbirds & Shape of Things \\
\hline 1967 & James Brown & Cold Sweat - Part 1 \\
\hline 1967 & The 5 th Dimension & Go Where You Wanna Go \\
\hline 1967 & The Animals & San Franciscan Nights \\
\hline 1967 & The Buckinghams & Kind of a Drag \\
\hline 1967 & The Byrds & Goin’ Back \\
\hline 1967 & Arthur Conley & Sweet Soul Musi \\
\hline 1967 & The Electric Prunes & I Had Too Much to Dream (Last Night) \\
\hline 1967 & The Four Tops & Standing in the Shadows of Love \\
\hline 1967 & Aretha Franklin & Chain of Fools \\
\hline 1967 & Aretha Franklin & I Never Loved a Man (The Way I Love You) \\
\hline 1967 & Marvin Gaye \& Tami Terrell & If I Could Build My Whole World Around You \\
\hline 1967 & Marvin Gaye \& Kim Weston & It Takes Two \\
\hline 1967 & Lesley Gore & California Nights \\
\hline 1967 & The Hollies & Carrie-Ann \\
\hline 1967 & The Music Explosion & Little Bit O’ Soul \\
\hline 1967 & The Music Machine & The People in Me \\
\hline 1967 & Nitty Gritty Dirt Band & Buy For Me the Rain \\
\hline 1967 & Roy Orbison & Cry Softly Lonely One \\
\hline 1967 & Wilson Pickett & I'm in Love \\
\hline 1967 & Wilson Pickett & Soul Dance Number Three \\
\hline 1967 & Elvis Presley & Judy \\
\hline 1967 & The Rolling Stones & Dandelion \\
\hline
\end{tabular}




\begin{tabular}{|c|c|c|}
\hline 1967 & Jimmy Ruffin & I've Passed This Way Before \\
\hline 1967 & Sagittarius & My World Fell \\
\hline 1967 & Simon \& Garfunkel & Fakin’ It \\
\hline 1967 & Sopwith Camel & Hello Hello \\
\hline 1967 & The Turtles & Happy Together \\
\hline 1967 & The Who & Happy Jack \\
\hline 1968 & The Amboy Dukes & Journey to the Center of the Mind \\
\hline 1968 & Blue Cheer & Summertime Blues \\
\hline 1968 & The Box Tops & Cry Like a Baby \\
\hline 1968 & Canned Heat & On the Road Again \\
\hline 1968 & Clarence Carter & Too Weak to Fight \\
\hline 1968 & Ray Charles & Eleanor Rigby \\
\hline 1968 & Joe Cocker & With a Little Help From My Friend \\
\hline 1968 & Cream & Sunshine of Your Love \\
\hline 1968 & Creedence Clearwater Revival & I Put a Spell on You \\
\hline 1968 & Dion & Abraham, Martin and John \\
\hline 1968 & Flatt \& Scruggs & Foggy Mountain Breakdown \\
\hline 1968 & Max Frost \& The Troopers & Shape of Things to Come \\
\hline 1968 & Iron Butterfly & In-A-Gadda-Da-Vida \\
\hline 1968 & Tommy James & Mony Mony \\
\hline 1968 & The Miracles & I Second That Emotion \\
\hline 1968 & Wilson Pickett & I Found a True Love \\
\hline 1968 & Elvis Presley & Guitar Man \\
\hline 1968 & Elvis Presley & If I Can Dream \\
\hline 1968 & The Rascals & People Got to Be Free \\
\hline
\end{tabular}




\begin{tabular}{|c|c|c|}
\hline 1968 & Otis Redding & (Sittin' On) The Dock of the Bay \\
\hline 1968 & Marty Robbins & I Walk Alone \\
\hline 1968 & Simon \& Garfunkel & Mrs. Robinson \\
\hline 1968 & Steppenwolf & Born to be Wild \\
\hline 1968 & The Temptations & I Wish It Would Rain \\
\hline 1968 & B.J. Thomas & Hooked On a Feeling \\
\hline 1968 & Jerry Jeff Walker & Mr. Bojangles \\
\hline 1969 & Badfinger & Maybe Tomorrow \\
\hline 1969 & The Beach Boys & Bluebirds Over the Mountain \\
\hline 1969 & The Beatles & Come Together \\
\hline 1969 & Brother Jack McDuff & Them From Electric Surfboard \\
\hline 1969 & Glen Campbell & Galveston \\
\hline 1969 & Glen Campbell & Wichita Lineman \\
\hline 1969 & Jimmy Cliff & Wonderful World, Beautiful People \\
\hline 1969 & The Cowsills & Hair \\
\hline 1969 & The Cowsills & Silver Threads and Golden Needles \\
\hline 1969 & Creedence Clearwater Revival & Bad Moon Rising \\
\hline 1969 & Crosby, Stills \& Nash & Judy Blue Eyes \\
\hline 1969 & The Isley Brothers & It's Your Thing \\
\hline 1969 & The Jacksons & I Want You Back \\
\hline 1969 & Tommy James & Crystal Blue Persuasion \\
\hline 1969 & Janis Joplin & Kozmic Blues \\
\hline 1969 & Little Anthony \& The Imperials & Out of Sight, Out of Mind \\
\hline 1969 & Peggy Lee & Is That All There Is? \\
\hline
\end{tabular}




\begin{tabular}{|c|c|c|}
\hline 1969 & The Miracles & Baby, Baby Don’t Cry \\
\hline 1969 & Oliver & Good Morning Starshine \\
\hline 1969 & The Rolling Stones & Honky Tonk Women \\
\hline 1969 & Sly \& The Family Stone & Hot Fun In the Summertime \\
\hline 1969 & Sly \& The Family Stone & I Want to Take You Higher \\
\hline 1969 & The Who & Pinball Wizard \\
\hline 1969 & The Youngbloods & Get Together \\
\hline 1970 & James Brown & Get Up (I Feel Like a) Sex Machine - Part 1 \\
\hline 1970 & Glen Campbell & It's Only Make Believe \\
\hline 1970 & Canned Heat & Let's Work Together \\
\hline 1970 & Clarence Carter & Patches \\
\hline 1970 & Chicago & 25 or 6 to 4 \\
\hline 1970 & Chicago & Does Anybody Really Know What Time It Is? \\
\hline 1970 & Chicago & Make Me Smile \\
\hline 1970 & Crosby, Stills \& Nash & Teach Your Children \\
\hline 1970 & B.B. King & The Thrill Is Gone \\
\hline 1970 & The Meters & Look-Ka Py Py \\
\hline 1970 & Elvis Presley & I Really Don't Want to Know \\
\hline 1970 & Ray Price & For the Good Times \\
\hline 1970 & Rare Earth & Get Ready \\
\hline 1970 & Jimmy \& David Ruffin & Stand By Me \\
\hline 1970 & Santana & Evil Ways \\
\hline 1970 & Simon \& Garfunkel & Cecilia \\
\hline 1970 & Simon \& Garfunkel & El Condor Pasa \\
\hline 1970 & Edwin Starr & War \\
\hline
\end{tabular}




\begin{tabular}{|c|c|c|}
\hline 1970 & The Supremes & Stoned Love \\
\hline 1970 & R. Dean Taylor & Indiana Wants Me \\
\hline 1970 & The Tee Set & Ma Belle Amie \\
\hline 1970 & Ike \& Tina Turner & I Want to Take You Higher \\
\hline 1971 & The 5th Dimension & Never My Love \\
\hline 1971 & The 5th Dimension & One Less Bell to Answer \\
\hline 1971 & The Band & Life Is a Carnival \\
\hline 1971 & Bread & If \\
\hline 1971 & Cornelius Brothers \& Sister Rose & Treat Her Like a Lady \\
\hline 1971 & The Doors & Riders of the Storm \\
\hline 1971 & Emerson, Lake \& Palmer & Lucky Man \\
\hline 1971 & Five Man Electric Band & Absolutely Right \\
\hline 1971 & Isaac Hayes & The Look of Love \\
\hline 1971 & Jimi Hendrix & Freedom \\
\hline 1971 & Elton John & Levon \\
\hline 1971 & Tom Jones & She's a Lady \\
\hline 1971 & Roberta Flack \& Donny Hathaway & You've Got a Friend \\
\hline 1971 & Marvin Gaye & Mercy Mercy me (The Ecology) \\
\hline 1971 & Tom T. Hall & The Year That Clayton Delaney Died \\
\hline 1971 & Gladys Knight \& The Pips & If I Were Your Woman \\
\hline 1971 & Kris Kristofferson & Loving Her Was Easier \\
\hline 1971 & The Miracles & I Don't Blame You at All \\
\hline 1971 & Graham Nash & Chicago \\
\hline 1971 & Ocean & Put Your Hand in the Hand \\
\hline 1971 & The Osmonds & One Bad Apple \\
\hline
\end{tabular}




\begin{tabular}{|l|l|l|}
$\mathbf{1 9 7 1}$ & Wilson Pickett & Don't Knock My Love - Part 1 \\
\hline $\mathbf{1 9 7 1}$ & Elvis Presley & There Goes My Everything \\
\hline $\mathbf{1 9 7 1}$ & Jerry Reed & Ko-Ko Joe \\
\hline $\mathbf{1 9 7 1}$ & The Rolling Stones & Wild Horses \\
\hline $\mathbf{1 9 7 1}$ & Sonny \& Cher & All I Ever Need Is You \\
\hline $\mathbf{1 9 7 1}$ & Rod Stewart & Maggie May \\
\hline $\mathbf{1 9 7 1}$ & James Taylor & Country Road \\
\hline $\mathbf{1 9 7 1}$ & Ten Years After & I'd Love to Change the World \\
\hline $\mathbf{1 9 7 1}$ & Bill Withers & Ain't No Sunshine \\
\hline $\mathbf{1 9 7 1}$ & Bobby Womack & That's the Way I Feel About Cha \\
\hline $\mathbf{1 9 7 1}$ & Stevie Wonder & If You Really Love Me \\
\hline
\end{tabular}

